\title{
INTERAKSI SOSIAL LANSIA DI BADAN PERLINDUNGAN SOSIAL TRESNA WERDHA (BPSTW) CIPARAY DENGAN KELUARGA
}

\author{
Oleh: \\ Ayu Martina, Budhi Wibhawa, \& Meilanny Budiarti S. \\ Email: \\ ayu.martina@gmail.com
}

\begin{abstract}
ABSTRAK
Orang yang sudah lanjut usia mengalami penurunan kemampuan fisik, sosial, motorik dan psikologis, sehingga pelayanan dan dukungan pada Lansia perlu mendapatkan perhatian yang besar dari keluarga. Berdasarkan data dari Badan Pusat Statistika Jawa Barat jumlah penduduk lansia pada 2013 mencapai 3.434.909 jiwa dari jumlah penduduk Jawa Barat 45.430.799 jiwa (BPS, 2013). Dalam lingkungan panti jompo lansia dapat berinteraksi dengan sesama lansia, petugas, bahkan dengan keluarganya sekalipun.

Adapun yang melatarbelakangi penelitian di BPSTW Pakutandang adalah interaksi sosial yang terjadi antara lansia denga keluarga di panti jompo ada yang berjalan dengan baik dan ada pula yang tidak berjalan dengan baik. Interaksi yang berjalan dengan baik membuat lansia itu masih merasakan rasa kasih sayang dari keluarganya meskipun lansia tersebut tinggal di panti jompo. Berbeda dengan lansia yang tidak dapat berinteraksi dengan keluarganya, akan merasakan kesepian dan kesehatannya pun menurun. Terdapat beberapa lansia di panti jompo merasakan kesepian akibat tidak adanya interaksi dengan keluarga, pihak panti pun menghubungi keluarga dari lansia tersebut agar keluarga dapat menjenguk atau berkomunikasi dengan lansianya.

Fenomena interaksi sosial yang terjadi pada lansia dengan keluarganya dapat berjalan dengan baik untuk kebaikan lansia yang tinggal di panti jompo. Sehingga, lansia tidak merasakan kesepian dan lansia dapat tetap sehat dengan adanya interaksi sosial. Pihak panti tersebut akan terus berusaha menghubungi keluarga lansia apabila ada kasus lansia yang merasa kesepian atau lansia yang rindu akan keluarganya agar interaksi sosial dapat berjalan dengan baik baik itu komunikasi secara langsung atau pun tidak langsung.
\end{abstract}

Kata Kunci: Interaksi sosial, Lansia, Keluarga

\section{ABSTRACT}

People who are elderly decreased physical ability, social, motor and psychological, so that services and support to elderly need to get the most attention from the family. Based on data from the Central Bureau of Statistics of West Java in 2013 the elderly population reached 3,434,909 inhabitants of the population of 45,430,799 inhabitants of West Java (CBS, 2013).

As for the background of the research in BPSTW Pakutandang is social interaction that occurs between premises elderly relatives in nursing homes there were going well and some are not going well. Interaction goes well make the elderly still feel affection of his family though the elderly 
living in nursing homes. In contrast to the elderly who are not able to interact with his family, will feel lonely and his health declined.

There are some elderly people in nursing homes feel lonely because no interaction with the family, the institution contacted the family of the elderly so that families can visit or communicate with lansianya.

The phenomenon of social interaction that occurs in the elderly with his family to work well for the benefit of elderly people living in nursing homes.

Keywords: social interaction, Seniors, Families

\section{PENDAHULUAN}

Lanjut usia merupakan perkembangan manusia yang telah mencapai umur 60 tahun atau lebih. Orang lanjut usia mengalami penurunan kemampuan fisik, sosial, motorik dan psikologis, sehingga pelayanan dan dukungan pada Lansia perlu mendapatkan perhatian yang besar dari keluarga. Berdasarkan data dari Badan Pusat Statistik Jawa Barat, jumlah penduduk lanjut usia pada 2013 mencapai 3.434.909 jiwa dari jumlah penduduk Jawa Barat 45.430.799 jiwa (BPS, 2013). Hal ini membuktikan bahwa penduduk lanjut usia di Jawa Barat memiliki angka harapan hidup yang kecil sehingga kualitas hidup penduduk lanjut usia perlu ditingkatkan untuk kesejahteraannya.

Orang-orang yang sudah lanjut usia dapat menikmati hidup dengan rasa senang, sehat, tenang, mempunyai keluarga yang bahagia, tidak merasa kesepian, anak cucu yang senantiasa dekat, lingkungan sosial yang mendukung aktivitas sesuai dengan kemampuannya, teman-teman yang dapat diajak berbagi cerita, dan kondisi spiritual yang baik (beribadah sesuai agama kepercayaannya). Ketika orang yang lanjut usia (lansia) tersebut tidak dapat menikmati hari tuanya karena adanya hambatan-hambatan dalam kemampuan dirinya dan lingkungan sekitar yang tidak mendukung, maka dapat disebut lansia yang tidak sejahtera. Jika ketidaksejahteraan itu diakibatkan oleh faktorfaktor luar seperti keluarga dan lingkungan sekitarnya, maka lansia tersebut dapat disebut lansia terlantar karena tidak terpenuhinya kebutuhan dasar dan sudah diatur dalam
Undang-Undang No.13 Tahun 1998 tentang Kesejahteraan Lansia.

Memerlukan interaksi yang baik dan intensif dalam merawat, menghargai dan mengapresiasi lansia, supaya para lanjut usia merasakan kenyamanan dalam berbagi cerita hidupnya. Pada dasarnya setiap manusia butuh untuk didengarkan. Sama halnya dengan lansia butuh orang yang dapat mendengarkan ceritanya dan paling penting keluarganya yang dapat menjadi tempat berbagi cerita. Adanya perhatian dari keluarga dapat membuat para lansia itu menjadi optimis, semangat, bahagia, tenang dalam sosialisasi, dan interaksi dengan masyarakat. Di dalam masyarakat, lansia juga mempunyai peranan penting yaitu sebagai guru dari pengalamnnya dalam menyelesaikan sebuah masalah.

Lembaga sosial merupakan suatu sistem dalam tata kelakuan untuk mengatur serangkaian tindakan manusia dalam bermasyarakat dan untuk memenuhi berbagai macam kebutuhan-kebutuhan dalam kehidupan masyarakat. Termasuk panti jompo tempat berkumpulnya para lansia yang sukarela maupun yang secara terpaksa diserahkan oleh keluarganya untuk tinggal di panti jompo agar dapat terpenuhi kebutuhan dasarnya. Menjamin dan memelihara setiap warga negara termasuk lansia merupakan tanggung jawab pemerintah yang sudah diatur dalam undang-undang tahun 1945 pasal 28 (AJ) tentang Hak Asasi Manusia.

\section{KAJIAN PUSTAKA}


Pelayanan yang terdapat dalam sebuah lembaga diharapkan dapat memberikan pelayanan yang baik bagi lansia juga keluarganya sehingga lansia tersebut merasa nyaman dan dapat mengatasi masalahnya sendiri. Y.B.Suparlan mengatakan bahwa, pelayanan adalah usaha untuk memberikan bantuan atau pertolongan kepada orang lain baik materi maupun non materi agar orang lain dapat mengatasi masalahnya sendiri, (Suparlan, 1983). Pelayanan untuk lansia baik dari keluarga atau lembaga dapat meningkatkan kualitas hidup penduduk lansia dan dapat mengaktualisasikan diri dalam keluarga dan masyarakat.

Selain pelayanan lansia di lembaga dapat juga menggunakan jasa perawat bagi lansia yang tinggal di rumah bersama keluarga bagi yang mampu menggunakan jasa perawat lansia di rumah, dengan demikian interaksi lansia dengan keluarganya masih dapat berjalan dengan baik tanpa harus menitipkan orang tua yang sudah lanjut usia ke lembaga sosial atau panti jompo. Para lanjut usia pun merasakan kebahagiaan, rasa nyaman, dan ketenangan tinggal di rumah bertemu dengan anak-anak, saudara dan cucu-cucunya. Keluarga ataupun lansia tersebut tidak khawatir akan sulitnya berkomunikasi secara langsung dengan orang-orang yang ada disekeliling lansia. Namun, untuk keluarga yang kurang dalam perekonomian keluarganya mereka akan lebih baik menitipkan orang tuannya yang sudah lanjut ke panti jompo supaya dapat terjamin kebutuhan dasarnya. Maka interaksinya pun berbeda dengan lansia yang dirawat di rumahnya, untuk lansia yang dirawat di lembaga keluarganya harus sering berkunjung ke lembaga menemui orang tuanya supaya komunikasinya bagus.

Berdasarkan paparan sebelumnya tentang fakta yang terjadi pada penduduk lanjut usia pada saat ini perlu kita ketahui keadaanya yang ada sebenarnya untuk melihat dan meneliti lebih lanjut tentang "Interaksi Sosial Lansia di BPTW Ciparay dengan Keluarga".
Lansia (lanjut usia) merupakan suatu perubahan perkembangan manusia yang alami. Proses penuaan akan terjadi kepada setiap manusia yang diberikan umur panjangan. Penuaan bukan sebuah penyakit akan tetapi itu proses perkembangan manusia secara alami. Menurut Nugroho W (2000):

"Menua (menjadi tua) adalah suatu proses menghilangnya secara perlahanlahan kemampuan jaringan untuk memperbaiki diri/mengganti dan mempertahankan fungsi normalnya sehingga tidak dapat bertahan terhadap infeksi dan memperbaiki kerusakan yang diderita." (Mujahidullah,2012:1)

Berikut beberapa batasan-batasan lanjut usia (lansia) dari beberapa sumber dan para ahli:

1. Menurut Departemen Kesehatan Republik Indonesia

a) Kelompok lansia dini (55-64 tahun)

b) Kelompok lansia pertengahan (65 tahun ke atas)

c) Kelompok lansia dengan resiko tinggi (70 tahun keatas)

2. Menurut Bernice Neu Gardon (1975)

a) Lansia muda, yaitu pada orang yang berumur antara 55-75 tahun

b) Lansia tua, yaitu orang yang berumur lebih dari 75 tahun

3. Menurut Levinson (1978)

a) Lansia peralihan awal, antara 50-55 tahun

b) Lansia peralihan menengah, antara 55-60 tahun

c) Lansia peralihan akhir, antara 6065 tahun

Dari beberapa pendapat para ahli dan lembaga terdapat banyak perbedaan tentang pengelompokan lanjut usia.

Lingkungan pertama untuk terjadinya interaksi sosial adalah keluarga. 
Keluarga inti terdiri dari Ayah, Ibu dan Anak, dimana adanya hubungan timbal balik yang saling mempengaruhi satu sama lainnya. Menurut Friedman (1998) keluarga adalah kumpulan dua orang atau lebih yang hidup bersama dengan keterikatan aturan dan emosional dan individu mempunyai peran masing-masing yang merupakan bagian dari keluarga.(Suprajitno,2004:1)

Interaksi sosial merupakan hubunganhubungan sosial yang dinamis yang menyangkut hubungan antara orang-orang perorangan, antara kelompok-kelompok manusia, maupun antara orang perorangan dengan kelompok manusia (Gillin dan Gillin dalam Soejono Soekanto, 1954).

Berlangsungnya suatu proses interaksi didasarkan pada berbagai faktor antara lain:

1. Imitasi

Faktor yang mendorong seseorang untuk mematuhi kaidah-kaidah dan nilai-nilai yang berlaku. Namun, ada dampak negatifnya juga yaitu mengikuti tindakantindakan yang menyimpang.

2. Sugesti

Faktor sugesti berlangsung apabila seseorang memberi suatu pandangan atau sesuatu sikap yang berasal dari dirinya yang kemudian diterima oleh pihak lain. Berlangsungnya sugesti yang terjadi karena pihak yang menerima dilanda oleh emosi yang menghambat daya berpikirnya secara rasional.

3. Identifikasi

Identifikasi merupakan kecenderungankecenderungan atau keinginan-keinginan dalam diri seseorang untuk menjadi sama dengan pihak lainnya. Proses identifikasi berlangsung dengan sendirinya, maupun dengan disengaja karena sering kali seseorang memerlukan tipe-tipe ideal tertentu di dalam proses kehidupan.

4. Simpati
Merupakan suatu proses dimana seseorang merasa tertarik pada pihak lain. Dorongan utama pada simpati adalah keinginan untuk memahami pihak lain dan untuk bekerja sama dengannya. (Soejono Soekanto, 2012:57)

\section{Interaksi Sosial Lanjut Usia dengan Keluarga}

Dalam penelitian ini, interaksi sosial yang dikaitkan dengan teori ini yaitu untuk mengetahuai interaksi sosial lansia dengan keluarga, yakni kunjungan keluarga (langsung menjenguk lansia ke panti), komunikasi dengan lansia (baik secara langsung face to face, ataupun dengan cara telepon, sms, surat, dan cara lainnya).

\section{SIMPULAN DAN SARAN}

\section{Kesimpulan}

Dari fenomena interaksi sosial lansia dengan keluarga di Badan Perlindungan Sosial Tresna Werdha (BPSTW) Ciparay terjadi interaksi positif maupun negatif yang terjadi antara lansia dengan keluarganya. Interaksi positif yaitu adanya hubungan yang baik antara keluarga dengan lansia yang tinggal di panti jompo, sehingga kebutuhan dasar lansia masih terpenuhi untuk merasakan kasih sayang dari keluarganya dan dengan adanya komunikasi yang baik dengan keluarga kesehatan lansia pun baik juga. Sedangkan, interaksi negatif yaitu tidak adanya komunikasi maupun kontak sosial antara lansia dengan keluarganya sehingga membuat lansia merasa kesepian dan kesehatannya menurun. Pihak panti akan berusaha menghubungi keluarga lansia agar dapat berinteraksi baik secara langsung atau pun tidak lansung sehingga lansia tidak merasakan kesepian dan kesehatannya pun tidak menurun.

2. Saran

\section{a) Pihak Panti}

Pelayan bagi lansia dapat lebih baik dan dapat menjaga interaksi sosial antara lansia 
dengan keluarganya sehingga lansia yang berada di panti jompo tidak merasa kesepian. Dapat berkomunikasi dengan baik dengan keluarga lansia agar dapat dengan mudah dalam menginformasikan tentang keadaan lansia yang tinggal di panti jompo.

\section{b) Pihak Keluarga}

Keluarga dapat menyempatkan waktunya untuk dapat mengunjungi lansia atau berkomunikasi baik langsung atau pun tidak lansung denga orang tuanya yang tinggal di panti jompo agar lansia tidak merasa kesepian dan tidak merasa terabaikan/terbuang oleh keluarganya.

\section{DAFTAR PUSTAKA}

Mujahidullah, Khalid. Keperawatan Geriatrik (merawat lansia dengan cinta dan kasih sayang). 2012. Yogyakarta: Pustaka Belajar

Soekanto Soejono,Sosiologi Suatu Pengantar.2012. Jakarta: Rajawali Pers

Suprajitno,Asuhan Keperawatan

Keluarga.2004.Jakarta:Buku Kedokteran EGC

www.jabar.bps.go.id 